\title{
Predictors for the quantity not sufficient sweat collection for ionic conductivity in newborns and young infants
}

\author{
Renata Bedran ${ }^{1}$, Cristina Alvim${ }^{1}$, Olívia Sader ${ }^{1}$, José Alves Júnior ${ }^{1}$, Fernando Pereira ${ }^{1}$, \\ Daniela Nolasco ${ }^{1}$, and Paulo Augusto Camargos ${ }^{1}$ \\ ${ }^{1} \mathrm{UFMG}$
}

February 23, 2021

\begin{abstract}
Background: Sweat conductivity (SC) is a semi-automated method widely used as a screening test for Cystic Fibrosis. Quantity not sufficient (QNS) is defined when collecting a volume lower than $15 \mu$ l of sweat during 30 minutes. Objective: To verify the rate and factors related to QNS for SC in newborns and young infants. Methods: Newborns and infants aged less than three months that had undergone sweat conductivity after two abnormal immunoreactive trypsinogen results, were recruited prospectively and consecutively. Statistical analysis included descriptive statistics, univariate and multivariate logistic regression. Results: A total of 1020 individuals were included. Among them, the rate of QNS was $8.9 \%$. Subjects with gestational age $<37$ weeks $(\mathrm{OR}=5.0)$, birth weight $<2.000 \mathrm{~g}(\mathrm{OR}=3.5)$, and daily weight gain $<25 \mathrm{~g} /$ day $(\mathrm{OR}=3.4)$ were more likely to produce an insufficient quantity of sweat. Conclusion: Our results suggest that QNS rates for SC could successfully fulfill the Cystic Fibrosis Foundation standards in newborns and young infants. In cases of QNS, SC should be scheduled as early as possible when the infant is older than 37 weeks (corrected age).
\end{abstract}

\section{Hosted file}

Predictors for QNS_CI.pdf available at https://authorea.com/users/346346/articles/510327predictors-for-the-quantity-not-sufficient-sweat-collection-for-ionic-conductivity-innewborns-and-young-infants

\section{Hosted file}

TAble 1.pdf available at https://authorea.com/users/346346/articles/510327-predictors-forthe-quantity-not-sufficient-sweat-collection-for-ionic-conductivity-in-newborns-andyoung-infants 